\title{
Inequality matters
}

\author{
Fiona Godlee editor in chief
}

The BMJ

Medicine has a class problem. While other professions have made progress in recruiting more students from disadvantaged backgrounds, medicine continues to lag behind. In Caroline White's report this week (doi:10.1136/bmj.16433), we hear that the proportion of UK medical students from lower socioeconomic backgrounds is half that among university students overall.

This matters. Not only because we want a profession that properly reflects the population it serves, but because we want the best and most able students to study medicine whatever school or family circumstances they come from.

Efforts to improve the situation continue. "Gateway courses" provide an extra initial year for students to catch up on what they have missed in their schooling, and a fifth of the newly created medical school places must go to students who are socially or educationally disadvantaged. These things should help. But social disadvantage continues during training, say medical students Anna Harvey and Declan Murphy on BMJ Opinion (https://blogs.bmj.com/bmj/2019/11/14/disadvantagesfaced-by-poorer-medical-students-must-be-challenged). "Having to work during holidays can mean opportunities to build your $\mathrm{CV}$ are missed, putting you in a worse position than more financially secure colleagues when applying for foundation jobs and specialty training."

Should medical schools lower their entry criteria, in particular by dropping the traditional requirement for an A level in chemistry? In our Head to Head article this week (doi:10.1136/ bmj.16456), Diana Wood and colleagues warn that this would be a mistake, though they support the idea of taking prospective students' backgrounds into account in admissions. A sound basis in science is essential, they say. Students who excel in chemistry perform better in medical school and are less likely to drop out. But Drew Tarmey argues that overall performance in tests such as the University Clinical Aptitude Test (UCAT) is a better measure than A level chemistry. Educationally disadvantaged students who are admitted with slightly lower A level grades often outperform their privately educated counterparts at medical school, he says.

Beyond the need for fairness or a representative profession, there is more immediate urgency. We are in the midst of a workforce crisis and we need the numbers. In case there is any doubt, one more symptom of this is the UK's poor performance in cancer survival, say Ruth Thorlby and Rebecca Fisher (doi:10. 1136/bmj.16122). Election promises of more funding are welcome, but, says Gareth Iacobucci in the latest of our Election Watch columns (doi:10.1136/bmj.16463), plans to rapidly increase the number of GPs look unrealisable from whichever political party they come.

Focusing on and tackling inequality at all levels in society will bring health dividends, and we know that there are important stories hiding within the routine data. So please do take up the challenge in our recently launched competition: to use NHS data to create data visualisations that shine light on our deeply embedded and damaging social and health inequalities (doi:10. 1136/bmj.16489; https://www.nuffieldtrust.org.uk/project/nhsvisual-data-challenge). 